\title{
Cytotoxic Spiroepoxide Lactone and Its Putative Biosynthetic Precursor from Goniobranchus Splendidus
}

\author{
Louise C. Forster, ${ }^{\dagger}$ Gregory K. Pierens, ${ }^{\ddagger}$ Andrew M. White, ${ }^{\dagger}$ Karen L. Cheney, ${ }^{\S}$ Pradeep Dewapriya," \\ Robert J. Capon, ${ }^{\| \odot}$ and Mary J. Garson* ${ }^{* \dagger}$
}

${ }^{\dagger}$ School of Chemistry and Molecular Biosciences, ${ }^{\dagger}$ Centre for Advanced Imaging, ${ }^{\S}$ School of Biological Sciences, and "Institute for Molecular Bioscience, The University of Queensland, Brisbane, 4072 QLD, Australia

Supporting Information

ABSTRACT: Epoxygoniolide-1 (1), possessing spiroepoxide lactone, enal, and masked dialdehyde functionalities, has been characterized from the conspicuously patterned mollusc Goniobranchus splendidus. Its relative configuration was investigated by spectroscopic analyses, molecular modeling, and density functional theory calculations. The biosynthesis of 1 may involve rearrangement of a diterpene framework, providing a precursor to cometabolite gonioline (2), followed by $\mathrm{C}-\mathrm{C}$ bond cleavage (via Grob or P450 mechanism). Moderate cytotoxicity to NCIH-460, SW60, or HepG2 cancer cells was observed for norditerpene 1.

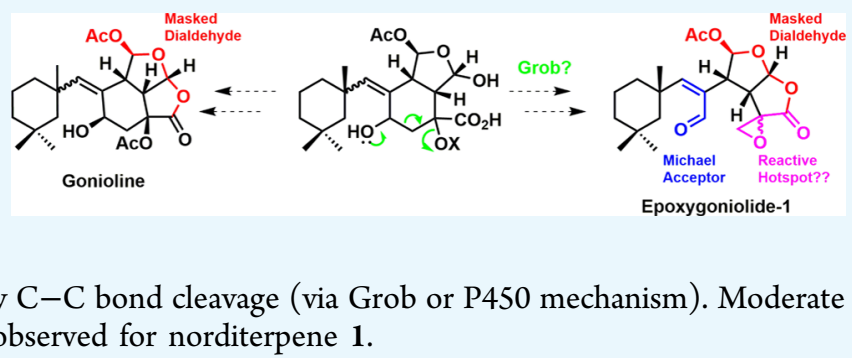

\section{INTRODUCTION}

Many animals use bright, colorful visual signals to warn potential predators that they store toxic or distasteful compounds as chemical defenses. In the marine environment, nudibranchs are shell-less molluscs that exhibit a range of conspicuous color signals, and many species contain terpene metabolites possessing anti-infective, ${ }^{1}$ anti-inflammatory, ${ }^{2}$ neuroprotective, ${ }^{3}$ and cytotoxic effects. ${ }^{1,4,5}$ Our quest to explore the chemistry underpinning the relationship between conspicuousness with toxicity has led us to uncover new terpene scaffolds from nudibranchs. ${ }^{6}$ Herein, we report the isolation and stereochemical characterization of two new norditerpenes, epoxygoniolide-1 (1) and gonioline (2), from the chromodorid mollusc Goniobranchus splendidus. The carbon framework of epoxygoniolide- 1 is richly decorated with structural motifs that are potential candidates for attack by amine, thiol, or hydroxy nucleophiles. Studies extend to a plausible biosynthesis involving a Grob-type fragmentation, as well as an assessment of the cytotoxic properties and stability of $\mathbf{1}$ against human cancer cells.

\section{RESULTS AND DISCUSSION}

A single specimen of G. splendidus, collected by scuba diving from the Great Barrier Reef near Mackay, North Queensland, was dissected into mantle rim, mantle, and gut tissue, with each tissue type extracted with acetone, partitioned into $\mathrm{Et}_{2} \mathrm{O}$ solubles, and analyzed by proton nuclear magnetic resonance $\left({ }^{1} \mathrm{H} \mathrm{NMR}\right)\left(\mathrm{CDCl}_{3}\right)$. The rim $(9.8 \mathrm{mg})$ and combined mantle/ viscera $(7.7 \mathrm{mg})$ extracts were separately fractioned by normalphase (NP) high-performance liquid chromatography (HPLC) to yield two new metabolites 1 and $\mathbf{2}$ (Figure 1), along with 16 known metabolites. Structure elucidation of the new metabolites was supported by detailed spectroscopic and computational analyses.
The major component of the extract, epoxygoniolide-1 (1), was isolated as a white amorphous solid and displayed a sodium adduct ion at $m / z 415.1730[\mathrm{M}+\mathrm{Na}]^{+}$, which corresponded to a molecular formula of $\mathrm{C}_{21} \mathrm{H}_{28} \mathrm{O}_{7}$, implying $8^{\circ}$ of unsaturation. The ${ }^{13} \mathrm{C}$ NMR data (Table 1 ) revealed 21 signals, including those for an acetate group, suggestive of a norditerpene skeleton. There were two alkene signals at $\delta_{\mathrm{C}} 134.9$ and 172.1, an $\alpha, \beta$-unsaturated aldehyde carbon at $\delta_{\mathrm{C}} 195.9$, and signals that could be attributed to a spiroepoxide $\left(\delta_{\mathrm{C}} 48.8\left(\mathrm{CH}_{2}\right)\right.$ and 58.0 (C)). ${ }^{8}$ The ${ }^{1} \mathrm{H}$ NMR spectrum revealed three methyl singlets at $\delta_{\mathrm{H}} 0.84,0.94$, and 1.16; an acetate methyl at $\delta_{\mathrm{H}} 2.03$; an alkene at $\delta_{\mathrm{H}} 6.96$; an aldehyde at $\delta_{\mathrm{H}} 9.35(\mathrm{~d})$; and two acetal protons at $\delta_{\mathrm{H}} 6.45(\mathrm{~d})$ and $6.65(\mathrm{~d})$. Two doublets at $\delta_{\mathrm{H}} 2.92$ and $3.15(J=5.2 \mathrm{~Hz})$ further supported the epoxide functionality.

Inspection of the gradient correlation spectroscopy (gCOSY), heteronuclear single-quantum coherence (HSQC), and heteronuclear multiple-bond correlation (HMBC) data established a planar structure for 1 (Figure 2). The trimethylcyclohexane fragment, common to rearranged diterpenes, ${ }^{6,7,9}$ was linked to the alkene through HMBC correlations from $\mathrm{H}-9$ at $\delta_{\mathrm{H}} 6.96$ to $\delta_{\mathrm{C}} 39.5(\mathrm{C}-1), 52.8(\mathrm{C}-5)$, and 30.7 (Me-19). H-7 $\left(\delta_{\mathrm{H}} 9.35\right)$ of the $\alpha, \beta$-unsaturated aldehyde gave HMBC correlations to $\delta_{\mathrm{C}} 43.1$ (C-14) and 172.1 (C-9). The 2,8-dioxabicyclo[3.3.0] octane ring system was apparent from gCOSY connectivities that linked $\mathrm{H}-14\left(\delta_{\mathrm{H}} 3.83\right)$ to both $\mathrm{H}-13$ $\left(\delta_{\mathrm{H}} 3.22\right)$ and $\mathrm{H}-15\left(\delta_{\mathrm{H}} 6.65\right)$, as well as $\mathrm{H}-13$ to $\mathrm{H}-16\left(\delta_{\mathrm{H}}\right.$ 6.45). There were HMBC correlations from $\delta_{\mathrm{H}} 6.65(\mathrm{H}-15)$ to $\delta_{\mathrm{C}} 45.1(\mathrm{C}-13)$ and the acetate carbonyl at $\delta_{\mathrm{C}} 168.8$, as well as correlations from $\delta_{\mathrm{H}} 6.45(\mathrm{H}-16)$ to $\delta_{\mathrm{C}} 99.3$ (C-15), 43.1 (C-

Received: May 21, 2017

Accepted: June 2, 2017

Published: June 15, 2017 

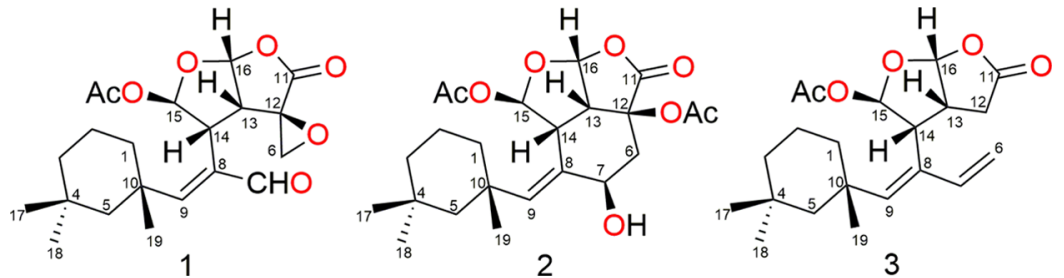

Figure 1. Chemical structures of norditerpenes 1-3 (with atom numbering based on that in the spongionellin (3) skeleton ${ }^{7}$ ).

Table 1. ${ }^{1} \mathrm{H}$ and ${ }^{13} \mathrm{C}$ NMR Data of 1 and 2 (in $\left.\mathrm{CDCl}_{3}\right)^{a, b}$

\begin{tabular}{|c|c|c|c|c|}
\hline \multirow[b]{2}{*}{ no. } & \multicolumn{2}{|r|}{1} & \multicolumn{2}{|r|}{2} \\
\hline & $\delta_{\mathrm{C}}$ & $\delta_{\mathrm{H}}($ mult. $J$ in $\mathrm{Hz}$ ) & $\delta_{\mathrm{C}}$ & $\delta_{\mathrm{H}}($ mult. $J$ in $\mathrm{Hz})$ \\
\hline 1a & 39.5 & 1.94, brd (13.3) & 42.2 & 1.75 , brd (13.1) \\
\hline $1 \mathrm{~b}$ & & $1.30, \mathrm{~m}$ & & $\begin{array}{l}1.07 \text {, ddd } \\
(13.1,12.7,3.8)\end{array}$ \\
\hline $2 \mathrm{a}$ & 19.7 & $1.59, \mathrm{~m}$ & 19.7 & $1.55, \mathrm{~m}$ \\
\hline $2 \mathrm{~b}$ & & $1.47, \mathrm{~m}$ & & $1.51, \mathrm{~m}$ \\
\hline $3 a$ & 38.8 & 1.38 , brd (13.3) & 39.0 & 1.36 , brd (13.2) \\
\hline $3 b$ & & $1.20, \mathrm{~m}$ & & $1.10, \mathrm{~m}$ \\
\hline 4 & 31.5 & & 31.5 & \\
\hline $5 a$ & 52.8 & $1.62, \mathrm{dt}(13.8,1.9)$ & 51.9 & $1.66, \mathrm{dt}(13.8,1.5)$ \\
\hline $5 b$ & & $1.33, \mathrm{~d}(13.8)$ & & $1.19, \mathrm{~d}(13.8)$ \\
\hline 6a & 48.8 & $3.15, d(5.2)$ & 40.4 & $2.53, \mathrm{dd}(13.7,4.4)$ \\
\hline $6 \mathrm{~b}$ & & $2.92, \mathrm{~d}(5.2)$ & & $2.10, \mathrm{dd}(13.7,9.4)$ \\
\hline 7 & 195.9 & $9.35, \mathrm{~d}(1.3)$ & 65.3 & $4.18, \mathrm{~m}$ \\
\hline 8 & 134.9 & & 130.5 & \\
\hline 9 & 172.1 & 6.96, brs & 137.7 & $6.13, \mathrm{~d}(1.4)$ \\
\hline 10 & 38.6 & & 35.3 & \\
\hline 11 & 170.8 & & 173.0 & \\
\hline 12 & 58.0 & & 78.2 & \\
\hline 13 & 45.1 & 3.22 , dd $(12.5,5.8)$ & 47.2 & 3.33, dd $(11.1,5.8)$ \\
\hline 14 & 43.1 & $\begin{array}{l}3.83, \mathrm{ddd} \\
(12.5,6.6,1.3)\end{array}$ & 43.3 & 3.95 , dd $(11.1,5.4)$ \\
\hline 15 & 99.3 & $6.65, \mathrm{~d}(6.6)$ & 99.8 & $6.15, \mathrm{~d}(5.4)$ \\
\hline 16 & 104.7 & $6.45, \mathrm{~d}(5.8)$ & 105.2 & 6.31, d (5.8) \\
\hline 17 & 33.0 & $0.94, \mathrm{~s}$ & 34.0 & $0.90, \mathrm{~s}$ \\
\hline 18 & 28.2 & $0.84, \mathrm{~s}$ & 28.5 & $0.84, \mathrm{~s}$ \\
\hline 19 & 30.7 & $1.16, \mathrm{~s}$ & 32.3 & $1.10, \mathrm{~s}$ \\
\hline 12-OAc & & & 170.3 & \\
\hline & & & 20.9 & $2.09, \mathrm{~s}$ \\
\hline 15-OAc & 168.8 & & 169.3 & \\
\hline & 20.9 & $2.03, \mathrm{~s}$ & 20.8 & $2.08, \mathrm{~s}$ \\
\hline $7-\mathrm{OH}$ & & & & $1.89, \mathrm{~d}(6.0)$ \\
\hline
\end{tabular}

${ }^{a}$ Recorded at 700 and $175 \mathrm{MHz}$ for ${ }^{1} \mathrm{H}$ and ${ }^{13} \mathrm{C}$ NMR, respectively. ${ }^{b}$ Chemical shifts $(\mathrm{ppm})$ referenced to $\mathrm{CHCl}_{3}\left(\delta_{\mathrm{H}} 7.26, \delta_{\mathrm{C}} 77.16\right)$.

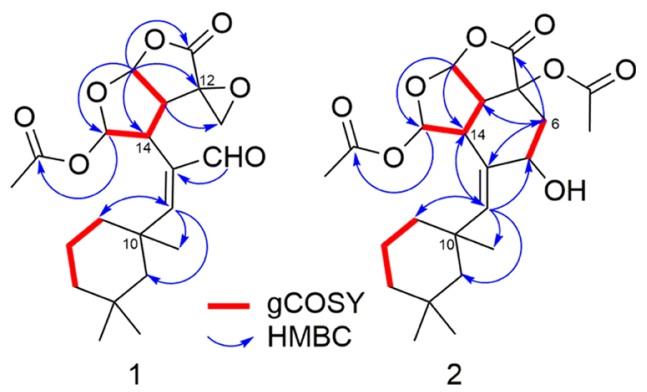

Figure 2. Selected two-dimensional (2D) NMR correlations of $\mathbf{1}$ and 2.

14), 58.0 (C-12), and the lactone at $\delta_{\mathrm{C}} 170.8$ (C-11). HMBC correlations from $\mathrm{H}-14$ and $\mathrm{H}-15$ to the quaternary alkene at $\delta_{\mathrm{C}}$
$134.9(\mathrm{C}-8)$ and from the epoxide protons $\mathrm{H}_{2}-6\left(\delta_{\mathrm{H}} 3.15\right.$ and $2.92)$ to the carbonyl $\mathrm{C}-11\left(\delta_{\mathrm{C}} 170.8\right)$ completed a planar carbon skeleton unprecedented in the natural products literature. A rotating-frame Overhauser spectroscopy (ROESY) correlation between $\mathrm{H}-7 / \mathrm{H}-9$ defined an $E$ configured alkene (Figure 3 ). The remaining stereochemistry is considered in detail below.
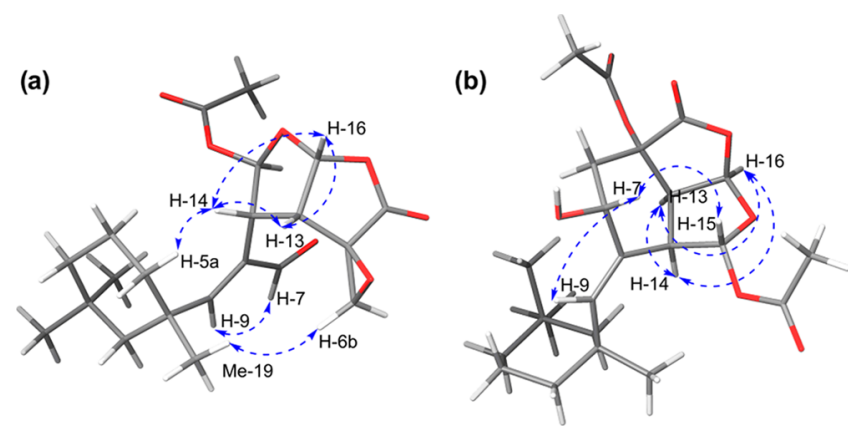

Figure 3. Energy-minimized stereostructures showing (a) selected ROESY correlations for $\mathbf{1}$ and (b) selected nuclear Overhauser enhancement spectroscopy (NOESY) correlations for 2.

Gonioline 2 was isolated by NP-HPLC (30\% EtOAc/ hexanes) as a colorless oil. The molecular formula of $\mathrm{C}_{23} \mathrm{H}_{32} \mathrm{O}_{8}$ was established by (+)-high-resolution electrospray ionization mass spectrometry (HRESIMS) $\left(\mathrm{m} / z 459.1993[\mathrm{M}+\mathrm{Na}]^{+}\right.$, calcd 459.1987), implying $8^{\circ}$ of unsaturation. Analysis of the ${ }^{13} \mathrm{C}$ NMR $\left(\mathrm{CDCl}_{3}\right)$ data for 2 (Table 1 ) provided 23 signals, including resonances attributed to two acetates $\left(\delta_{\mathrm{C}} 170.3,20.9\right.$; and 169.3, 20.8), an ester/lactone $\left(\delta_{\mathrm{C}} 173.0\right)$, and a trisubstituted olefin $\left(\delta_{\mathrm{C}} 137.7\right.$ and 130.5), implying a tetracyclic norditerpene. Diagnostic 2D NMR $\left(\mathrm{CDCl}_{3}\right)$ gCOSY, HSQC, and $\mathrm{HMBC}$ correlations established the carbon skeleton for 2 (Figure 2). The trimethylcyclohexane ring was linked to an alkene by $\mathrm{HMBC}$ correlations from $\delta_{\mathrm{H}} 6.13(\mathrm{H}-9)$ to $\delta_{\mathrm{C}} 42.2$ $(\mathrm{C}-1), 51.9(\mathrm{C}-5)$, and $32.3(\mathrm{Me}-19)$ and from $\delta_{\mathrm{H}} 1.19(\mathrm{H}-5 \mathrm{~b})$ to $\delta_{\mathrm{C}} 137.7$ (C-9). The presence of a cyclohexyl-fused tetrahydrofuranfuranone moiety was established by gCOSY connections that linked $\mathrm{H}-14\left(\delta_{\mathrm{H}} 3.95\right)$ to $\mathrm{H}-13\left(\delta_{\mathrm{H}} 3.33\right)$ and $\mathrm{H}-15\left(\delta_{\mathrm{H}} 6.15\right)$ as well as $\mathrm{H}-13$ to $\mathrm{H}-16\left(\delta_{\mathrm{H}} 6.31\right)$ and by an $\mathrm{HMBC}$ correlation from $\mathrm{H}-13$ to $\mathrm{C}-6\left(\delta_{\mathrm{C}} 40.4\right)$. There were also gCOSY correlations from $\mathrm{H}_{2}-6\left(\delta_{\mathrm{H}} 2.53\right.$ and 2.10) to the $\mathrm{H}-7$ oxymethine $\left(\delta_{\mathrm{H}} 4.18\right)$, and HMBC correlations from $\mathrm{H}_{2}-6$ to the C-11 carbonyl $\left(\delta_{\mathrm{C}} 173.0\right)$. HMBC correlations from $\delta_{\mathrm{H}}$ $6.13(\mathrm{H}-9)$ to $\delta_{\mathrm{C}} 65.3(\mathrm{C}-7)$ and $\delta_{\mathrm{C}} 43.3$ (C-14), from $\mathrm{H}-14$ to $\mathrm{C}-9$, and from $\left(\mathrm{H}_{2}-6\right)$ to the quaternary alkene carbon at $\delta_{\mathrm{C}}$ 130.5 then completed the planar structure of gonioline. The tricyclic ring system of $\mathbf{2}$ is similar to that of chromodorolide $\mathrm{B}^{10}$ or darwinolide, ${ }^{11}$ except for the replacement of the cyclopentyl or cycloheptenyl ring by a cyclohexyl ring. An E- 
Scheme 1. Putative Biosynthetic Relationships of 1 and 2 and Their Link to a Spongian Terpene Framework $(X=O H$ or OR)

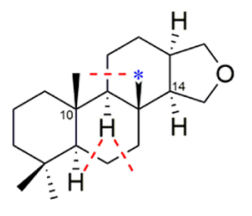

4

Regular spongian terpene skeleton
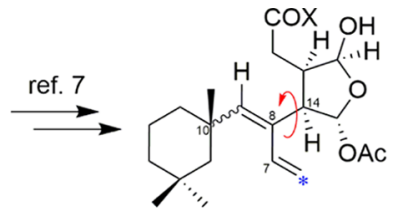

5

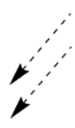

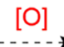

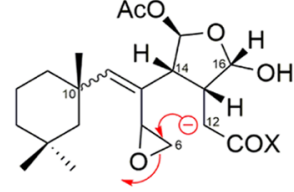

1. Cyclization

2. Oxidation at $\mathrm{C}-12$
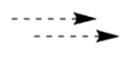

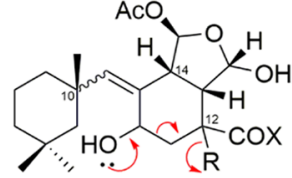

$6 \mathrm{R}=\mathrm{OH}$

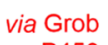

or P450

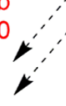

$7 \mathrm{R}=\mathrm{OAC}$

Lactonization vìn

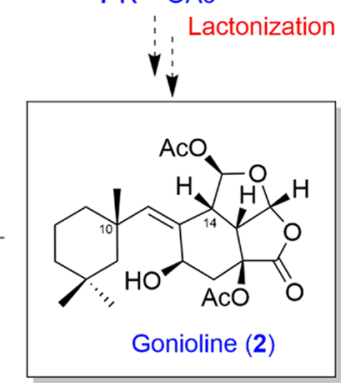

Spongionellin (3)
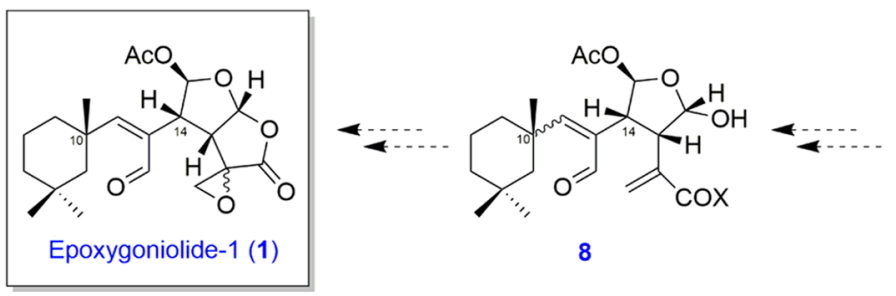

configured alkene was assigned from a NOESY correlation between $\mathrm{H}-7$ and $\mathrm{H}-9$.

NOESY correlations between $\mathrm{H}-14$ and $\mathrm{H}-16$; $\mathrm{H}-13$ and $\mathrm{H}-$ 16; and $\mathrm{H}-13$ and $\mathrm{H}-14$ revealed the same configuration of the tetrahydrofuran ring in 1 and 2 (Figure 3). The $J_{\mathrm{H}-14 / \mathrm{H}-15}$ values were 6.6 and $5.4 \mathrm{~Hz}$, respectively, which are comparable to the $J$ values of macfarlandin C (see Tables S1 and S2). In rearranged terpenes such as norrisolide, ${ }^{12}$ macfarlandin $\mathrm{C},{ }^{13}$ and chromodorolide $\mathrm{B},{ }^{10}$ for which identical relative configurations of the 2,8-dioxabicyclo[3.3.0] octane ring system have been secured by X-ray crystallographic analysis, the published ${ }^{1} \mathrm{H}$ NMR data show that a small change in conformation can have a significant effect on the magnitude of $J_{\mathrm{H}-14 / \mathrm{H}-15}$ associated with the tetrahydrofuran ring. ${ }^{13}$ The cyclohexyl-fused ring of 2 adopts a flattened chair conformation owing to the alkene linkage (Figure 3 ), with the axially configured $\mathrm{H}-7$ evidenced by vicinal couplings to $\mathrm{H}-6 \mathrm{a}(J=4.4 \mathrm{~Hz})$ and $\mathrm{H}-6 \mathrm{~b}(J=9.4 \mathrm{~Hz})$. The NOESY correlation observed between $\mathrm{H}-7$ and $\mathrm{H}-15$ defined the relative configuration at C-7, whereas $\mathrm{H}-13$ and 12OAc were positioned in the less-strained cis configuration rather than in the alternative trans configuration.

To resolve the remaining stereochemical features of $\mathbf{1}$, we exploited the possibility that the gonioline skeleton may constitute a biosynthetic link between the spongian ring system commonly encountered in nudibranch and sponge diterpenes 5 and the unique spiroepoxide framework of $\mathbf{1}$ (Scheme 1). First, the spongian precursor (4) is converted to the carbon skeleton (5), associated with the spongionellin series of metabolites, by C-17 methyl migration, oxidative cleavage of C-5-C-6 involving the loss of C-6, and cleavage of the C-9-C-11 bond. In this way, the C- 8 methyl group of the spongian precursor provides the C- 6 carbon of the spongionellin framework. ${ }^{7}$ Epoxidation of the C-6-C-7 bond is followed by cyclohexyl ring formation, yielding allylic alcohol intermediate 6. The cyclization yielding $\mathbf{6}$ is formally classified as a disfavored 6-endo-tet reaction by Baldwin's rules, but the fact that the cleaved $\mathrm{C}-\mathrm{O}$ bond lies outside the newly formed ring is consistent with 6-exo cyclization. ${ }^{14}$ Enzymatic control has been proposed as an explanation for anti-Baldwin ring closure of epoxides in biosynthesis. ${ }^{15}$ Oxidation at C-12 followed by acetylation provides intermediate 7 ; subsequent lactone formation then gives gonioline (2). The C-6-C-7 bond and the 12-OAc group of $\mathbf{2}$ are optimally oriented from a

stereoelectronic perspective for bond cleavage via a Grob-type mechanism (Figure 4a), ${ }^{16,17}$ thereby generating the exo-

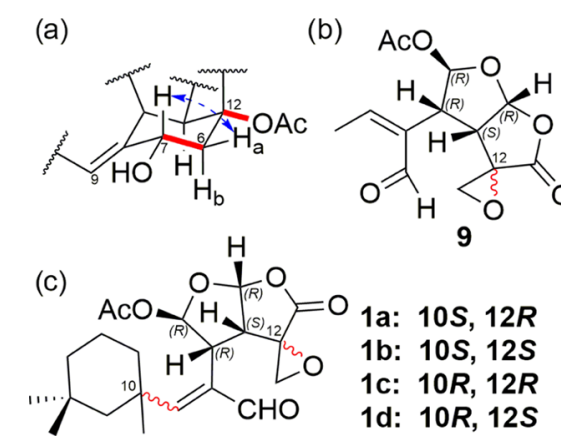

Figure 4. (a) Cyclohexyl-fused ring of 2 showing stereoelectronic alignment compatible with a Grob-type fragmentation; (b) model compound 9; (c) candidate stereoisomers $1 \mathbf{a}-\mathbf{d}$.

methylene-functionalized intermediate $\mathbf{8}$ from either $\mathbf{2}$ or, more simply, its immediate precursor, 6. Subsequent epoxidation and lactone formation then leads directly to the carbon skeleton of $\mathbf{1}$. Alternatively, the key $\mathrm{C}-\mathrm{C}$ bond cleavage forming 8 might involve a P450-catalyzed transformation, with a mechanism similar to that involved in homoterpene, psoralen, or secologanin biosynthesis, ${ }^{18}$ in which case, prior functionalization at $\mathrm{C}-12$ is not required.

From a stereochemical perspective, and arbitrarily selecting the $10 S$ configuration frequently associated with marine diterpenes, ${ }^{19}$ this biosynthetic scenario predicts a $13 S, 14 R, 15 R, 16 S$ configuration for the 2,8-dioxabicyclo[3.3.0]octane ring. To probe the spiroepoxide $(\mathrm{C}-12)$ configuration of $\mathbf{1}$, the truncated structure $(\mathbf{9})$, in which a methyl group replaced the conformationally flexible trimethylcyclohexane ring, was selected for computational analysis (Figure 4b). A Monte Carlo conformational search of the $12 R$ and $12 S$ stereoisomers of 9 was undertaken with the Optimized Potential for Liquid Simulations (OPLS)-2005 force field, and next, selected conformers ( $<3 \mathrm{kcal} / \mathrm{mol}$ of the global minimum) were optimized by (density functional theory) DFT calculations at the B3LYP/6-31G(d) level in the gas phase using Gaussian software. The structures were further refined using B3LYP/ 631-G+(d,p) with chloroform as solvent (IEF-PCM), and the isotropic shielding constants computed from these energies 
were then examined using the DP4+ approach; ${ }^{20}$ considering both ${ }^{1} \mathrm{H}$ and ${ }^{13} \mathrm{C}$ data, there was $99.89 \%$ probability that $\mathrm{C}-12$ of $\mathbf{9}$, and, by implication, that of $\mathbf{1}$ was $R$-configured. To further verify this stereochemical conclusion, molecular modeling and DFT calculations were conducted on two candidate stereoisomers of $\mathbf{1}$ ( $\mathbf{1} \mathbf{a}$ and $\mathbf{1 b}$ ) that differed in configuration at C-12 and on two diastereomers with the biosynthetically unlikely $10 R$ absolute configuration ( $1 c$ and $1 d$ ) (Figure $4 c$ ). The energies associated with DFT-refined structures were used to calculate the Boltzmann-averaged ${ }^{1} \mathrm{H}$ NMR and ${ }^{13} \mathrm{C}$ NMR chemical shifts of the four stereoisomers (see Supporting Information); the calculated mean absolute error values ${ }^{21}$ did not discriminate between the four diastereomers, but when the isotropic shielding constants computed from these energies were examined using DP4+ with both ${ }^{1} \mathrm{H}$ and ${ }^{13} \mathrm{C}$ NMR data, there was $90.39 \%$ probability that the $10 S^{*}, 12 R^{*}$ configuration was the correct stereoisomer of $\mathbf{1}$. ROESY data for $\mathbf{1}$ further supported the proposed stereochemistry, with correlations from the epoxide proton $\mathrm{H}-6 \mathrm{~b}$ to $\mathrm{Me}-19$ as well as from $\mathrm{H}-5 \mathrm{a}$ to $\mathrm{H}$ 14 , fully consistent with the proposed relative configuration (see Figure 3). In each of the three lowest energy conformers of stereoisomer 1a (together representing $>96.5 \%$ of the conformational population and with only minor differences in the conformation of the trimethylcyclohexane ring), one of the epoxide protons was within $3.29 \AA$ of the centroid of Me-19. In the alternative stereoisomers, $\mathbf{1} \mathbf{b}-\mathbf{d}$, one or more of the internuclear distances corresponding to these ROESY correlations were $>5 \AA$.

Previous studies have explored the cytotoxicity of oxygenated diterpenes and norditerpenes, with varying levels of activity reported. ${ }^{1,4,5}$ Terpene $\mathbf{1}$ is embellished with three potentially bioactive structural motifs: a diacetal acetate moiety that masks the potential dialdehyde reactivity, ${ }^{22}$ an $\alpha, \beta$-unsaturated aldehyde susceptible to Michael addition, ${ }^{23}$ and a spiroepoxide $^{24}$ accessible to nucleophilic attack in the presence of free amino or thiol groups. Indeed, a spiroepoxide moiety positioned $\alpha$ to a carbonyl group is the "warhead" central to the catalytic mechanism of a family of proteasome inhibitors (e.g., epoxomicin and its synthetic analogue carfilzomib). ${ }^{25}$ However, when epoxygoniolide-1 (1) was screened against human lung (NCIH-460), colorectal (SW620), and liver (HepG2) cancer cells, using vinblastine as a positive control, the metabolite showed modest $\mathrm{IC}_{50}$ values of $10.2,10.18$, and $15.72 \mu \mathrm{M}$, respectively. In view of this finding, we assessed the stability of 1 under a range of conditions. An NMR study in $\mathrm{MeOH}-d_{4}$ revealed that 1 was stable in this solvent over a $24 \mathrm{~h}$ period. Norditerpene $\mathbf{1}$ was also stable in dimethyl sulfoxide solution at $40{ }^{\circ} \mathrm{C}$, either alone or in the presence of alanine methyl ester hydrochloride as a potential scavenger of a dialdehyde product. In the presence of the above-mentioned cancer cell lines, the epoxide concentration declined over 6-12 $\mathrm{h}$ in a manner that paralleled toxicity. A mass spectrometric search for acetyl-cleavage products, Michael adducts, or epoxide-hydrolyzed products in the culture medium did not detect any definable products and so it was not possible to discern which molecular feature of $\mathbf{1}$ might be responsible for the observed bioactivity.

There was insufficient quantity of gonioline (2) for cytotoxicity screening. A parallel screening of four oxygenated norditerpenes isolated from nudibranchs ${ }^{6}$ gave $\mathrm{IC}_{50}$ values in the range of $2.1-24.5 \mu \mathrm{M}$ against human lung (NCIH-460), colorectal (SW620), and liver (HepG2) cancer cells (see Supporting Information). Taken together with the data for $\mathbf{1}$, a pattern of moderate cytotoxicity emerged for this suite of norditerpenes, from which we infer that these metabolites may instead be utilized by the mollusc as an antipredator defense. Assays with crustaceans and fish have indicated nudibranch extracts containing spongian diterpenes, norditerpenes, or rearranged diterpenes have antipalatability activity that prevails over their toxicity. ${ }^{22,26}$

\section{CONCLUSIONS}

We isolated two new oxygenated terpenes from the nudibranch G. splendidus, each with an extensively rearranged skeleton. We provided the first example of epoxide substitution onto the 2,8dioxabicyclo[3.3.0] octane ring system, contributing significant structural variation to this distinctive scaffold. Owing to the complex arrangement of stereochemical elements, we resorted to in-silico analysis using DFT calculations and DP4+ modeling to identify a statistically reasonable diastereomer of $\mathbf{1}$. The spiroepoxide lactone motif of $\mathbf{1}$ is compatible with a biosynthetic origin involving cleavage of the C-6-C-7 bond of a precursor to 2 via either a Grob-type fragmentation or a P450-induced cleavage. Moderate cytotoxicity was associated with the spiroepoxide. The presence of $\mathbf{1}$ and $\mathbf{2}$ in the gut of G. splendidus provides circumstantial evidence of a dietary (i.e., sponge) origin.

\section{EXPERIMENTAL SECTION}

4.1. General Experimental Procedures. Optical rotations were obtained using a Jasco P-2000 polarimeter at $589 \mathrm{~nm}$ using a $1 \mathrm{~mL}$ quartz cell $(10 \mathrm{~cm}$ path length) for solutions in $\mathrm{CHCl}_{3}$. NMR spectra were recorded at ambient probe temperature on a Bruker Avance 500 spectrometer using a 5 mm selective inverse probe or a Bruker Avance DRX 700 spectrometer with a $5 \mathrm{~mm}$ triple resonance Zgrad probe. All of the NMR spectra were acquired in base-filtered $\mathrm{CDCl}_{3}$ and referenced to solvent signals at $\delta_{\mathrm{H}} 7.26$ and $\delta_{\mathrm{C}} 77.16\left(\mathrm{CDCl}_{3}\right)$. Low-resolution electrospray ionization mass spectrometry was performed on a Bruker Esquire HCT three-dimensional ion trap spectrometer in the positive mode. HRESIMS was performed on a MicroTof-Q instrument with a standard ESI source (sodium formate). HPLC was carried out using a $10 \mu \mathrm{m}$ silica $(7.8 \times 300)$ column with refractive index detection. Separations were performed using isocratic solvent conditions up to $30 \%$ EtOAc in hexanes at $2 \mathrm{~mL} / \mathrm{min}$ using premixed, filtered, and degassed solvents.

4.2. Biological Material. The nudibranch specimen was collected from the Mackay region of the Great Barrier Reef, North Queensland, by scuba diving at depths between 2 and 15 $\mathrm{m}$. The sample was stored at $-20{ }^{\circ} \mathrm{C}$ until extraction. Photographs of the specimen (G. splendidus \#1102) were kept at the School of Chemistry and Molecular Biosciences, University of Queensland.

4.3. Extraction and Purification. Prior to extraction, the specimen was dissected into viscera, mantle, and mantle border body segments. Individually, each body segment was finely chopped, extracted with acetone $(3 \times 2 \mathrm{~mL})$, and sonicated $(5$ min). Each extract was filtered through cotton wool and concentrated to an aqueous suspension before partitioning between $\mathrm{H}_{2} \mathrm{O}(1 \mathrm{~mL})$ and $\mathrm{Et}_{2} \mathrm{O}(3 \times 1 \mathrm{~mL})$. The upper organic layer was retained, dried over anhydrous $\mathrm{Na}_{2} \mathrm{SO}_{4}$, filtered through cotton wool, and evaporated under $\mathrm{N}_{2}$ to yield a yellow oil for the mantle $(2.9 \mathrm{mg})$, mantle rim $(9.8 \mathrm{mg})$, and gut $(4.8$ $\mathrm{mg}$ ). The crude extracts were screened by ${ }^{1} \mathrm{H} \mathrm{NMR}$, and all 
showed similar chemistry. The crude extract of the mantle rim was filtered and the compounds were separated using NPHPLC (30\% EtOAc in hexanes) to yield dendrillolide $\mathrm{A}^{27}(0.2$ $\mathrm{mg})$, aplysulphurin ${ }^{28}(0.2 \mathrm{mg})$, macfarlandin $\mathrm{E}^{13}(0.2 \mathrm{mg})$, macfarlandin $C^{13}(0.2 \mathrm{mg})$, spongionellin ${ }^{7}(3)(0.1 \mathrm{mg})$, macfarlandin $\mathrm{D}^{13}(0.4 \mathrm{mg})$, chromodorolide $\mathrm{A}^{29}(0.1 \mathrm{mg})$, $7 \beta, 11 \beta$-diacetoxy-16-oxospongi-12en-17-al ${ }^{30}(0.1 \mathrm{mg})$, aplyroseol- $2^{31}(0.1 \mathrm{mg})$, aplyroseol- $3^{31}(0.2 \mathrm{mg})$, splendidalactone$1^{6 \mathrm{a}}(0.1 \mathrm{mg})$, epoxygoniolide- $1(1)(1.0 \mathrm{mg})$, and gonioline 2 $(0.1 \mathrm{mg})$. The crude extracts of the mantle and gut were combined and filtered, and the compounds were separated using NP-HPLC (25\% EtOAc in hexanes) to isolate spongian16-one ${ }^{32,33}(0.2 \mathrm{mg})$, 9,11-dihydrogracilin $\mathrm{A}^{34}(0.1 \mathrm{mg})$, gracilin $\mathrm{A}^{35}(0.2 \mathrm{mg})$, dendrillolide $\mathrm{A}^{27}(0.2 \mathrm{mg})$, aplysulphurin $^{28}(0.2 \mathrm{mg})$, macfarlandin $\mathrm{E}^{13}(0.4 \mathrm{mg})$, macfarlandin $\mathrm{C}^{13}$ $(0.4 \mathrm{mg})$, spongionellin ${ }^{7} 3(0.5 \mathrm{mg})$, norrisolide ${ }^{12}(0.3 \mathrm{mg})$, macfarlandin $\mathrm{D}^{13}(0.4 \mathrm{mg}), 7 \beta, 11 \beta$-diacetoxy-16-oxospongi$12 \mathrm{en}-17-\mathrm{al}^{30}(0.2 \mathrm{mg})$, aplyroseol- $2^{31}(0.3 \mathrm{mg})$, aplyroseol- $3^{31}$ $(0.4 \mathrm{mg})$, splendidalactone- $1^{6 \mathrm{a}}(0.1 \mathrm{mg})$, tetrahydroaplysul-

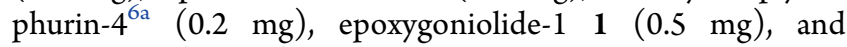
gonioline $2(0.1 \mathrm{mg})$.

4.3.1. Epoxygoniolide-1 (1). Colorless oil (1.5 mg); $[\alpha]^{23}+$ 32 (c $\left.0.05, \mathrm{CHCl}_{3}\right) ;{ }^{1} \mathrm{H}$ and ${ }^{13} \mathrm{C} \mathrm{NMR}\left(\mathrm{CDCl}_{3}, 700 \mathrm{MHz}\right)$, Table 1; (+)-HRESIMS $m / z 415.1730[\mathrm{M}+\mathrm{Na}]^{+}$(calcd for $\left.\mathrm{C}_{21} \mathrm{H}_{28} \mathrm{NaO}_{7}, 415.1727\right)$.

4.3.2. Gonioline (2). Colorless oil $(0.2 \mathrm{mg})$; $[\alpha]^{23}{ }_{\mathrm{D}}-37(c$ $\left.0.01, \mathrm{CHCl}_{3}\right) ;{ }^{1} \mathrm{H}$ and ${ }^{13} \mathrm{C} \mathrm{NMR}\left(\mathrm{CDCl}_{3}, 700 \mathrm{MHz}\right)$, Table 1; (+)-HRESIMS $m / z$ 459.1993 $[\mathrm{M}+\mathrm{Na}]^{+}$(calcd for $\mathrm{C}_{23} \mathrm{H}_{32} \mathrm{NaO}_{8}, 459.1987$ ).

\section{ASSOCIATED CONTENT}

\section{S Supporting Information}

The Supporting Information is available free of charge on the ACS Publications website at DOI: 10.1021/acsomega.7b00641.

Details of extraction and isolation, other experimental procedures, modeling and computational studies, cytotoxicity assays, and copies of one-dimensional and 2D NMR spectra of compounds 1 and 2 (PDF)

\section{AUTHOR INFORMATION}

\section{Corresponding Author}

*E-mail: m.garson@uq.edu.au. Tel: +61-7-3365 3605. Fax: +61-7-3365 4273 .

\section{ORCID}

Robert J. Capon: 0000-0002-8341-7754

Mary J. Garson: 0000-0001-8670-1075

\section{Notes}

The authors declare no competing financial interest.

\section{ACKNOWLEDGMENTS}

Financial support from the Australian Science Pacific Foundation, Computational resources were provided by the NCI NF (Australia). Discussions with Prof. J. De Voss and Dr. E. Krenske as well as the assistance of Dr. A. Winters (dissection), Dr. T. Le (NMR), and G. McFarlane (MS) are appreciated. The nudibranch specimen was collected under permit by Dr. A. Roberts-Thomson (QLD Sustainable Sealife Ltd).

\section{REFERENCES}

(1) Betancur-Galvis, L.; Zuluaga, C.; Arnó, M.; González, M. A.; Zaragozá, R. J. J. Nat. Prod. 2002, 65, 189-192.

(2) Keyzers, R. A.; Northcote, P. T.; Zubkov, O. A. Eur. J. Org. Chem. 2004, 2004, 419-425.

(3) Leirós, M.; Alonso, E.; Rateb, M. E.; Houssen, W. E.; Ebel, R.; Jaspars, M.; Alfonso, A.; Botana, L. M. Neuropharmacology 2015, 93, 285-293.

(4) Rueda, A.; Losada, A.; Fernandez, R.; Cabanas, C.; GarciaFernandez, L. F.; Reyes, F.; Cuevas, C. Lett. Drug Des. Discovery 2006, 3, 753-760.

(5) Keyzers, R. A.; Northcote, P. T.; Davies-Coleman, M. T. Nat. Prod. Rep. 2006, 23, 321-334.

(6) (a) White, A. M.; Pierens, G. K.; Forster, L. C.; Winters, A. E.; Cheney, K. L.; Garson, M. J. J. Nat. Prod. 2016, 79, 477-483.

(b) Hirayama, Y.; Katavic, P. L.; White, A. M.; Pierens, G. K.; Lambert, L. K.; Winters, A. E.; Kigoshi, H.; Kita, M.; Garson, M. J. Aust. J. Chem. 2016, 69, 136-144.

(7) Mayol, L.; Piccialli, V.; Sica, D. Tetrahedron 1986, 42, 53695376.

(8) Rodríguez, A. D.; Piña, I. C.; Acosta, A. L.; Ramírez, C.; Soto, J. J. J. Org. Chem. 2001, 66, 648-658.

(9) Díaz-Marrero, A. R.; Dorta, E.; Cueto, M.; San-Martín, A.; Darias, J. Tetrahedron 2004, 60, 1073-1078.

(10) (a) Morris, S. A.; de Silva, E. D.; Andersen, R. J. Can. J. Chem. 1991, 69, 768-771. (b) Tao, D. J.; Slutskyy, Y.; Overman, L. E. J. Am. Chem. Soc. 2016, 138, 2186-2189.

(11) von Salm, J. L.; Witowski, C. G.; Fleeman, R. M.; McClintock, J. B.; Amsler, C. D.; Shaw, L. N.; Baker, B. J. Org. Lett. 2016, 18, 25962599.

(12) Hochlowski, J. E.; Faulkner, D. J.; Matsumoto, G. K.; Clardy, J. J. Org. Chem. 1983, 48, 1141-1142.

(13) Molinski, T. F.; Faulkner, D. J.; He, C. H.; Van Duyne, G. D.; Clardy, J. J. Org. Chem. 1986, 51, 4564-4567.

(14) Vilotijevic, I.; Jamison, T. F. Mar. Drugs 2010, 8, 763-809.

(15) (a) Gallimore, A. R. Nat. Prod. Rep. 2009, 26, 266-280. (b) Mao, X.-M.; Zhan, Z.-J.; Grayson, M. N.; Tang, M.-C.; Xu, W.; Li, Y.-Q.; Yin, W.-B.; Lin, H.-C.; Chooi, Y.-H.; Houk, K. N.; Tang, Y. J. Am. Chem. Soc. 2015, 137, 11904-11907.

(16) Prantz, K.; Mulzer, J. Chem. Rev. 2010, 110, 3741-3766.

(17) Xiong, Q.; Wilson, W. K.; Matsuda, S. P. T. Angew. Chem., Int. Ed. 2006, 45, 1285-1288.

(18) (a) Boland, W. Pure Appl. Chem. 1993, 65, 1133-1142. (b) De Voss, J. J.; Cryle, M. J. Met. Ions Life Sci. 2007, 3, 397-435.

(19) (a) Hambley, T. W.; Taylor, W. C.; Toth, S. Aust. J. Chem. 1997, 50, 391-394. (b) Graham, S. K.; Garson, M. J.; Bernhardt, P. V. J. Chem. Crystallogr. 2010, 40, 468-471.

(20) Grimblat, N.; Zanardi, M. M.; Sarotti, A. M. J. Org. Chem. 2015, $80,12526-12534$.

(21) Bally, T.; Rablen, P. R. J. Org. Chem. 2011, 76, 4818-4830.

(22) Carbone, M.; Gavagnin, M.; Haber, M.; Guo, Y.-W.; Fontana, A.; Manzo, E.; Genta-Jouve, G.; Tsoukatou, M.; Rudman, W. B.; Cimino, G.; Ghiselin, M. T.; Mollo, E. PLoS One 2013, 8, No. e62075.

(23) Witz, G. Free Radical Biol. Med. 1989, 7, 333-349.

(24) Grieco, P. A.; Oguri, T.; Burke, S.; Rodriguez, E.; DeTitta, G. T.; Fortier, S. J. Org. Chem. 1978, 43, 4552-4554.

(25) (a) Zabala, D.; Cartwright, J. W.; Roberts, D. M.; Law, B. J. C.; Song, L.; Samborskyy, M.; Leadlay, P. F.; Micklefield, J.; Challis, G. L. J. Am. Chem. Soc. 2016, 138, 4342-4345. (b) Kim, K. B.; Crews, C. M. Nat. Prod. Rep. 2013, 30, 600-604.

(26) Winters, A. E. Understanding Colour and Chemical Diversity in Nudibranchs. Ph.D. Thesis,The University of Queensland, 2016.

(27) Bobzin, S. C.; Faulkner, D. J. J. Org. Chem. 1989, 54, 57275731.

(28) Karuso, P.; Skelton, B.; Taylor, W.; White, A. Aust. J. Chem. 1984, 37, 1081-1093.

(29) Dumdei, E. J.; De Silva, E. D.; Andersen, R. J.; Choudhary, M. I.; Clardy, J. J. Am. Chem. Soc. 1989, 111, 2712-2713. 
(30) McPhail, K.; Davies-Coleman, M. T. Tetrahedron 1997, 53, 4655-4660.

(31) Karuso, P.; Taylor, W. Aust. J. Chem. 1986, 39, 1629-1641.

(32) Kernan, M. R.; Cambie, R. C.; Bergquist, P. R. J. Nat. Prod. 1990, 53, 724-727.

(33) Hambley, T.; Poiner, A.; Taylor, W. Aust. J. Chem. 1990, 43, $1861-1870$.

(34) Molinski, T. F.; Faulkner, D. J. J. Org. Chem. 1987, 52, 296-298.

(35) Mayol, L.; Piccialli, V.; Sica, D. Tetrahedron Lett. 1985, 26, 1357-1360. 